Research Article

\title{
Development of Reaction Kinetics Model for the Production of Synthesis Gas from Dry Methane Reforming
}

\author{
Abrar Inayat1,2,*), Muhammad A.B. Ahmad ${ }^{3}$, Mohsin Raza ${ }^{4}$, Chaouki Ghenai ${ }^{1,2}$, \\ Salman Raza Naqvi ${ }^{5}$, Muhammad Ayoub ${ }^{3}$
}

${ }^{1}$ Department of Sustainable and Renewable Energy Engineering, University of Sharjah, 27272 Sharjah, United Arab Emirates.

${ }^{2}$ Biomass \& Bioenergy Research Group, Center for Sustainable Energy and Power Systems Research, Research Institute of Sciences and Engineering, University of Sharjah, 27272 Sharjah, United Arab Emirates.

${ }^{3}$ Chemical Engineering Department, Universiti Teknologi PETRONAS, Bandar Seri Iskandar, 31750 Tronoh, Perak, Malaysia.

${ }^{4}$ Department of Chemical \& Petroleum Engineering, United Arab Emirates University (UAEU), Al-Ain, United Arab Emirates.

${ }^{5}$ School of Chemical \& Materials Engineering, National University of Sciences \& Technology, 44000, Islamabad, Pakistan.

Received: 3rd March 2021; Revised: 1st May 2021; Accepted: $5^{\text {th }}$ May 2021

Available online: $6^{\text {th }}$ May 2021; Published regularly: June 2021

\section{Abstract}

The energy supply systems dependent on fossils and municipal solid waste (MSW) materials are primarily responsible for releasing greenhouse (GHG) gases and their related environmental hazards. The increasing amount of methane $\left(\mathrm{CH}_{4}\right)$ and carbon dioxide $\left(\mathrm{CO}_{2}\right)$ is the scientific community's main concern in this context. Reduction in the emission amount of both gases combined with the conversion technologies that would convert these total threat gases $\left(\mathrm{CO}_{2}\right.$ and $\left.\mathrm{CH}_{4}\right)$ into valuable feedstocks will significantly lower their hazardous impact on climate change. The conversion technique known as dry methane reforming (DMR) utilizes $\mathrm{CO}_{2}$ and $\mathrm{CH}_{4}$ to produce a combustible gas mixture $\left(\mathrm{CO}+\mathrm{H}_{2}\right)$, popularly known as synthesis gas/or syngas. Therefore, this research study aims to explore and enlighten the characteristics of the DMR mechanism. The conversion behaviour of $\mathrm{CO}_{2}$ and $\mathrm{CH}_{4}$ was studied with modelling and simulation of the DMR process using MATLAB. The results showed that inlet gas flow has a significant impact on the reactions. In contrast, the inlet molar composition ratio of the reactions was found to have no substantial effect on the mechanism of DMR.

Copyright (C) 2021 by Authors, Published by BCREC Group. This is an open access article under the CC BY-SA License (https://creativecommons.org/licenses/by-sa/4.0).

Keywords: Greenhouse gases; Synthesis gas; Dry Methane Reforming; Reaction Kinetics Modelling

How to Cite: A. Inayat, M.A.B. Ahmad, M. Raza, C. Ghenai, S.R. Naqvi, M. Ayoub (2021). Development of Reaction Kinetics Model for the Production of Synthesis Gas from Dry Methane Reforming. Bulletin of Chemical Reaction Engineering \& Catalysis, 16(2), 440-445 (doi:10.9767/bcrec.16.2.10510.440-445)

Permalink/DOI: https://doi.org/10.9767/bcrec.16.2.10510.440-445

\section{Introduction}

Carbon monoxide $(\mathrm{CO})$ and hydrogen $\left(\mathrm{H}_{2}\right)$ have high significance as feedstock for various

* Corresponding Author.

Email: ainayat@sharjah.ac.ae (A. Inayat);

Tel: +971-5-653972 chemical processes in the process and manufacturing industry. These gases $\left(\mathrm{CO}+\mathrm{H}_{2}\right)$ can be produced by multiple commercialized methods like coal/or biomass gasification, partial oxidation of fossil fuel oil, and steam reforming methane. The mixture of gas $\left(\mathrm{CO}+\mathrm{H}_{2}\right)$ is known as syntheses gas or syngas [1,2]. Synthesis gas is 
usually converted into petrochemicals, synthetic fuels, and higher alcohols [3,4]. Carbon monoxide is widely used in the production of paints, plastics, foams, pesticides, and insecticides; meanwhile, hydrogen is used in ammonia synthesis and petroleum refining industries [5].

Methane reforming is the leading method of producing syngas, supplying more than $80 \%$ of the world's synthesis gas [6]. The most costeffective method of synthesis gas production and gas production includes other predominant processes, such as: naphtha reforming, fuel oil partial oxidation, and coal gasification [7]. Useless $\mathrm{CO}_{2}$ can be converted into the synthesis gas $\left(\mathrm{CO}+\mathrm{H}_{2}\right)$ by the process of dry reforming of methane (DRM) which uses the natural gas for its reaction mechanism [8]. Synthesis gas $\left(\mathrm{CO}+\mathrm{H}_{2}\right)$ can also be produced by the simultaneous transformation of the two significant greenhouses (GHG) gases $\left(\mathrm{CO}_{2}\right.$ and $\left.\mathrm{CH}_{4}\right)$ in a process called catalytic reforming of methane [9].

For the past several decades, hydrogen $\left(\mathrm{H}_{2}\right)$ production was produced by the steam methane reforming (SMR) process. The method is preferred for the synthesis of pure $\mathrm{H}_{2}$ and its production at a large scale in ammonia manufacturing. Fischer-Tropsch conversion processes have facilitated the alteration of carboncontaining gases into the synthesis gas $\left(\mathrm{CO}+\mathrm{H}_{2}\right)$ more efficiently during the recent scientific era [10]. The conversion of methane $\left(\mathrm{CH}_{4}\right)$ and carbon dioxide $\left(\mathrm{CO}_{2}\right)$ into synthesis gas $\left(\mathrm{CO}+\mathrm{H}_{2}\right)$ took place based on several reactions, including carbon dioxide reduction by methane, reverse water-gas shift (RWGS) equation, methane decomposition, and reverse Boudouard reactions [8,11,12].

The reaction expressed by equation 3 is the main reaction of the dry methane reforming (DMR) process. This reaction is endothermic; therefore, heat will be absorbed in this stage of the process. Methane $\left(\mathrm{CH}_{4}\right)$ reacts with carbon dioxide $\left(\mathrm{CO}_{2}\right)$ on the active surface of the solid catalyst to form equimolar synthesis gas. The conversion efficiency of the reaction is improved by supplying $\mathrm{CO}_{2}$ in the excess amount. For this reaction to occur, the right amount of methane $\left(\mathrm{CH}_{4}\right)$ must be applied to reduce carbon dioxide $\left(\mathrm{CO}_{2}\right)$ convert it into $\mathrm{CO}$ and $\mathrm{H}_{2}$. This reaction typically occurs over Ni-based catalysts at the temperature ranging from 550 $1000{ }^{\circ} \mathrm{C}[13]$.

The reverse water-gas shift reaction (RWGS) converted the $\mathrm{CO}_{2}$ and produced $\mathrm{H}_{2}$ into carbon monoxide (CO) and water vapors $\left(\mathrm{H}_{2} \mathrm{O}\right)$. This reaction is also endothermic and requires heat for its execution and completion.
The reversal nature of water-gas shift reaction is essential for its versatility in applications i-e in ammonia production. Most frequently, the reaction is done using a copper or aluminum catalyst [13-15]. Several industries have practiced the RWGS process for converting cheap and invaluable $\mathrm{CO}_{2}$ into synthetic $\mathrm{CO}$, which is precious gas in the process industry.

Dry methane reforming (DMR) produces less hydrogen $\left(\mathrm{H}_{2}\right)$ than the $\mathrm{H}_{2}$ produced by the steam reforming process (SRM). Therefore, the dry methane process (DMR) has more feasibility for the biogas, which is already a mixture of $\mathrm{CH}_{4}$ and $\mathrm{CO}_{2}$ as the final product from the anaerobic digestion $(\mathrm{AD})$ process. There is no additional need for a downstream separation process for $\mathrm{CO}_{2}$ removal. For dry methane reforming (DMR) there are several kinds of carbon formation on Ni-based catalyst [14-16]. The reactions contribute to carbon deposition on the surface of the catalyst during the complete formation process cycle. The reverse Boudouard reaction represented is limited at high temperatures. However, the methane decomposition reaction described in equation 3 is thermodynamically more favorable at high temperatures. There should be the application of catalysts that can inhibit the carbon formation and its deposition at the reaction condition $[17,18]$.

In this project, a kinetic reaction model was developed to predict the products and investigate the effect of temperature on final product composition using MATLAB. The work is significant towards highlighting the DMR process for producing $\mathrm{CO}$ and $\mathrm{H}_{2}$ from MSW and better understanding its reaction mechanism. It contributes to the utilization of greenhouse gases for energy production. Hydrogen has many applications and is considered the best clean and energy densified fuel. There is not much data available in the literature to perform the kinetic data analysis for DMR.

The work is also important because of the alarming situation of environmental pollution. Global warming resulting from large quantities of greenhouse gases (GHG), mainly $\mathrm{CO}_{2}$ emitted to the atmosphere, is the most significant environmental hazard. Thus, future research is focusing on developing technologies that enable the utilization of renewable and carbon-neutral resources.

\section{Materials and Methods}

The study's goal and scope were to develop the reaction kinetics model for the dry reforming of methane (DMR). To perform parametric analysis for the synthesis gas production from 
carbon dioxide and methane that was produced from municipal solid waste (MSW) and to calculate all the independent variables such as reaction kinetics constant and activation energy using optimization approach (MATLAB optimization toolbox) [19]. It is available to perform design optimization tasks, including kinetic parameter estimation, selection of components. This tool is very useful for studying the feasibility of processes and finding the optimal solutions. It is a key to efficient energy management and production planning. Few assumptions have been considered during the modeling and optimization approach, including steadystate conditions, reaction proceeds isothermally at constant volume, four main reactions considered for product calculations.

The rate of a chemical reaction can be attributed to its active chemical species' concentration by a relation known as rate law [20]. The active chemical species include reactants, products, and the catalysts involved. Every reaction has its rate of reaction, which is defined by Equation 1-2.

$$
\begin{aligned}
& r_{i}=k C_{a} C_{b} \\
& k=A_{i} \exp ^{-\frac{E a}{R T}}
\end{aligned}
$$

Four main parameters have been identified, including gas flow rate, inlet molar composition, mole percentage and temperature. Process developing and modeling the reaction process was conducted based on four main reactions simulated in MATLAB software as shown in Equations (3)-(6).
Carbon Dioxide reduction by Methane

$$
\mathrm{CO}_{2}+\mathrm{CH}_{4} \leftrightarrow 2 \mathrm{CO}+2 \mathrm{H}_{2}
$$

Reverse Water-Gas Shift (RWGS) reaction

$$
\mathrm{CO}_{2}+\mathrm{H}_{2} \leftrightarrow \mathrm{CO}+\mathrm{H}_{2} \mathrm{O}
$$

Methane decomposition

$$
\mathrm{CH}_{4} \leftrightarrow \mathrm{C}+2 \mathrm{H}_{2}
$$

Reverse Boudouard reaction

$$
\mathrm{C}+\mathrm{CO}_{2} \leftrightarrow 2 \mathrm{CO}
$$

MATLAB function $\mathrm{m}$-files were developed by writing function codes. The function $\mathrm{m}$-files being developed with the objectives of producing the final guess value of all independent variables such as activation energy $(E a)$ and reaction rate constant $(k)$ throughout the optimization process [21]. The MATLAB simulation optimization was carried out using the experimental data taken from literature for studying the reaction kinetics of the dry methane reforming (DMR) process. The flowchart in Figure 1 showed the optimization approach used for reaction kinetics parameters calculations. Reaction kinetics constants were obtained and extended for parametric study. The gas flow conditions at the inlet feed were set constant at $3600 \mathrm{~mL} / \mathrm{h}$ and $5400 \mathrm{~mL} / \mathrm{h}$ with an equal molar ratio $\left(\mathrm{CH}_{4}: \mathrm{CO}_{2}=1: 1\right)$.

\section{Results and Discussion}

Table 1 shows the kinetic parameters calculated from the four reactions considered for re-

Reaction kinetics parameters $A_{i}, E_{i}$

\section{Minimum value of residual based on experimental and modelling results}

$$
\text { residual }=\sum_{i=1}^{N}\left(\frac{y_{e}-y_{m}}{y_{e}}\right)^{2}
$$

$y_{e}=$ Experimental values

$y_{m}=$ Model predictions
Kinetics model based on four reactions (Dry reforming of methane)

$$
\begin{aligned}
& r_{i}=k_{i} C_{A} C_{B} \\
& k_{i}=A_{i} \exp ^{-\frac{E_{i}}{R T}}
\end{aligned}
$$

Result of product gas $\left(\mathrm{H}_{2}, \mathrm{CO}, \mathrm{CO}_{2}, \mathrm{CH}_{4}\right)$

Figure 1. Flowchart for optimization of reaction kinetics parameters of dry methane reforming reactions. 
action kinetics modeling of dry methane reforming. Reactions (2) and (3) have the highest values of negative activation energies. Figure 2 showed the product gases $\mathrm{CH}_{4}, \mathrm{CO}_{2}, \mathrm{H}_{2}$, and $\mathrm{CO}$ using $3600 \mathrm{~mL} / \mathrm{h}$ with a temperature range of $650-850{ }^{\circ} \mathrm{C}$. The mole percentages of all four components were plotted against temperature. It has been observed that as the temperature increases from 650 to $850{ }^{\circ} \mathrm{C}$, there has been a constant increase in the conversion of both $\mathrm{CH}_{4}$ and $\mathrm{CO}_{2}$ (decline in mole \%) and consequently an increase in the amount (mole \%) of $\mathrm{H}_{2}$ and $\mathrm{CO}$. The decrease in the mol \% of $\mathrm{CO}_{2}$ becomes constant at around $720{ }^{\circ} \mathrm{C}$, but $\mathrm{CH}_{4}$ mole \% shows a decrease until $8500^{\circ} \mathrm{C}$. Also, at this molar flow rate, mole \% of $\mathrm{CO}$ increases significantly up to $750{ }^{\circ} \mathrm{C}$. However, there has been a continuous increase in $\mathrm{H}_{2}$ mol \% up to $850{ }^{\circ} \mathrm{C}$, which shows that higher temperature is favora-

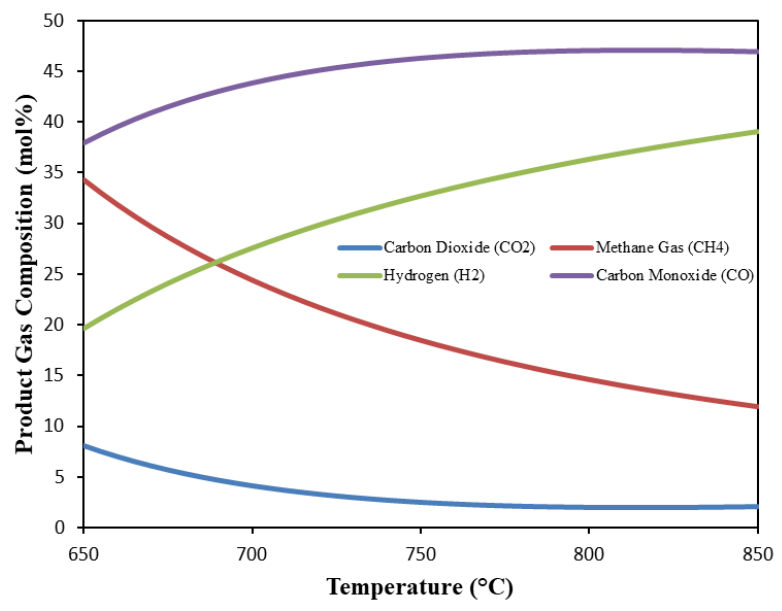

Figure 2. Effect of temperature on product gas composition (mol\%) at the gas inlet flow 3600 $\mathrm{mL} / \mathrm{h}$.

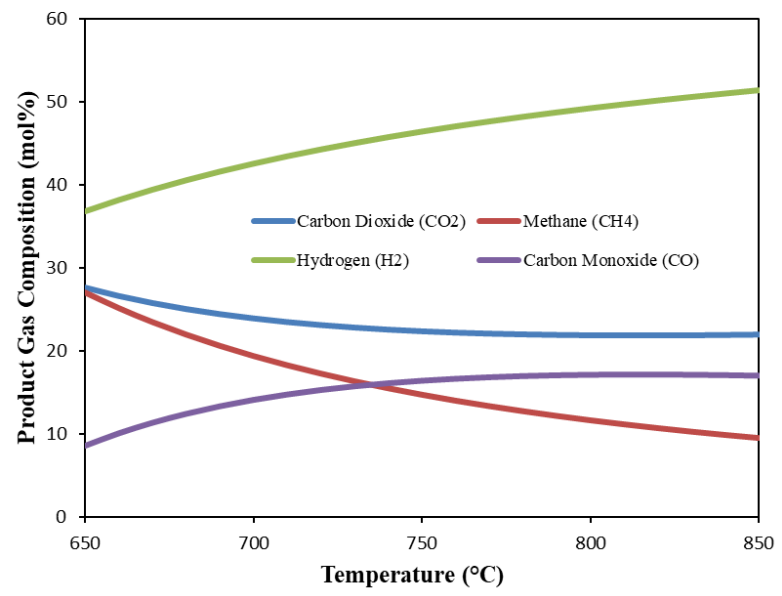

Figure 3. Effect of temperature on product gas composition (mol\%) at the gas inlet flow 5400 $\mathrm{mL} / \mathrm{h}$. ble for $\mathrm{H}_{2}$ yields. Also, there has been a more sharp increase in $\mathrm{H}_{2}$ mole \% with an increase in temperature.

Similar trends have been observed in the literature by Al-Ali et al. [22]. They performed the study in a temperature range of $600-900$ ${ }^{\circ} \mathrm{C}$ in a direct contact bubble column. The temperature was found to affect the reaction kinetics mainly. Due to this invention, an optimization strategy was practical to implement and understand the trade-off between high production rates and elevated $\mathrm{CO}_{2}$ and $\mathrm{CH}_{4}$ consumption rates in dry methane reforming. The increase in $\mathrm{H}_{2}$ and $\mathrm{CO}$ is mainly caused by the endothermic behavior of reactions involved in the dry methane reforming process.

Furthermore, an increase in the conversion of both reactants $\left(\mathrm{CH}_{4}\right.$ and $\left.\mathrm{CO}_{2}\right)$ was observed due to the reverse water gas shift reaction, methane decomposition, and revers Boudouard reactions. However, different reaction rates for $\mathrm{CH}_{4}$ and $\mathrm{CO}_{2}$ were obtained, which was attributed to the undesired formation of water during the reaction. At each point of reaction, the $\mathrm{CO}_{2}$ conversion is more than $\mathrm{CH}_{4}$ conversion, and on the product side, the increase in the $\mathrm{CO} \mathrm{mol} \%$ is always more significant than the rise in $\mathrm{mol} \%$ of $\mathrm{H}_{2}$.

Figure 3 shows the results obtained from predicted results after optimization at the inlet gas flow of $5400 \mathrm{~mL} / \mathrm{h}$. The graph shows when the influence of inlet gas flow is significantly vital as the inlet gas flow increased, the methane and carbon dioxide conversions were both affected. The small carbon monoxide increment in Figure 3 shows that the higher inlet gas flow is not suitable within the range of temperature $650-850{ }^{\circ} \mathrm{C}$. Higher molar flow rate results in higher molar production of $\mathrm{H}_{2}$. $\mathrm{CO}$ molar \% decrease with an increase in the gas inlet flow rate. Hence, together with temperature inlet molar flow rate of gas also plays a vital role.

The higher the gas flow, the higher the temperature needed for the reactions. Simultane-

Table 1. Kinetics parameters determined using an optimization approach.

\begin{tabular}{ccc}
\hline \multirow{2}{*}{ No } & \multicolumn{2}{c}{ Reaction Kinetics } \\
\cline { 2 - 3 } & $\begin{array}{c}\text { Reaction rate } \\
\text { constant }(k)\end{array}$ & $\begin{array}{c}\text { Activation } \\
\text { Energy }(E a)\end{array}$ \\
\hline 1 & 0.04 & -1285.29 \\
2 & 0.03 & -2747.62 \\
3 & 1.10 & -2714.71 \\
4 & -2.31 & -716.13 \\
\hline
\end{tabular}


ously, the inlet gas velocity of the syngas production is not produced in maximum value. A trade-off between high production rate and elevated $\mathrm{CO}_{2}$ and $\mathrm{CH}_{4}$ consumption rate in dry methane reforming has been observed due to a change in the flowrate. It is also recommended for an additional active optimization attitude to maximize the use of the entire reactant (inlet gas); a suitable inlet gas flow needs to be identified to produce the highest yield of synthesis gas.

\section{Conclusion}

This study was carried out with the main objective: developing the reaction kinetics model for the dry methane reforming and performing parametric analysis for the hydrogen and carbon monoxide production from greenhouse gases produced from landfills gas. Furthermore, to calculate the reaction kinetics constant using optimization approach (MATLAB optimization toolbox). An operative tool, the dry methane reforming model, was established to assess all the independent variables of activation energy value and reaction kinetics constant value $(k)$. This value indicates how successfully all the independent variables towards producing syngas can be referred to as a general kinetics model for dry methane reforming as future references. The essential features of the reaction mechanism of dry methane reforming were identified via a modeling approach. Gas-phase kinetics has a significant consequence on the production of syngas. The higher the temperature, the better the conversion achieved until a specific limit. Based on the effects of using the same molar composition ratio with increasing inlet gas flow results, it can be concluded that the inlet gas flow in a gas phase reaction is also dominant to the reactions. In addition, it is recommended to perform the fullscale optimization of the process to identify the best optimum operating conditions.

\section{Acknowledgments}

The authors would like to acknowledge the University of Sharjah, UAE research funds through Competitive Grant (18020406114).

\section{References}

[1] Wilhelm, D.J., Simbeck, D.R., Karp, A.D., Dickenson, R.L. (2001). Syngas production for gas-to-liquids applications: technologies, issues and outlook. Fuel Processing Technology, 71(1), 139-148. DOI: 10.1016/S03783820(01)00140-0

[2] Inayat, A., Inayat, M., Shahbaz, M., Sulaiman, S.A., Raza, M., Yusup, S. (2020). Parametric analysis and optimization for the catalytic air gasification of palm kernel shell using coal bottom ash as catalyst. Renewable Energy, 145, 671-681. D O I: 10.1016/j.renene.2019.06.104

[3] Inayat, A., Ghenai, C., Naqvi, M., Ammar, M., Ayoub, M., \& Hussin, M.N.B. (2017). Parametric Study for Production of Dimethyl Ether (DME) As a Fuel from Palm Wastes. Energy Procedia, 105, 1242-1249. DOI: 10.1016/j.egypro.2017.03.431

[4] Shahbaz, M., Yusup, S., Pratama, A., Inayat, A., Patrick, D.O., Ammar, M. (2016). Parametric Study and Optimization of Methane Production in Biomass Gasification in the Presence of Coal Bottom Ash. Procedia Engineering, 148, 409-416. DOI: 10.1016/j.proeng.2016.06.432

[5] Chaos, M., Dryer, F.L. (2008). Syngas Combustion Kinetics and Applications. Combustion Science and Technology, 180(6), 10531096. DOI: $10.1080 / 00102200801963011$

[6] Chen, L., Qi, Z., Zhang, S., Su, J., Somorjai, G.A. (2020). Catalytic Hydrogen Production from Methane: A Review on Recent Progress and Prospect. Catalysts, 10(8), 858. DOI: 10.3390/catal10080858

[7] Kaiwen, L., Bin, Y., Tao, Z. (2018). Economic analysis of hydrogen production from steam reforming process: A literature review. Energy Sources, Part B: Economics, Planning, and Policy, 13(2), 109-115. DOI: 10.1080/15567249.2017.1387619

[8] Abdulrasheed, A., Jalil, A.A., Gambo, Y., Ibrahim, M., Hambali, H.U., Shahul Hamid, M. Y. (2019). A review on catalyst development for dry reforming of methane to syngas: Recent advances. Renewable and Sustainable Energy Reviews, 108, 175-193. DOI: 10.1016/j.rser.2019.03.054

[9] Zhao, X., Joseph, B., Kuhn, J., Ozcan, S. (2020). Biogas Reforming to Syngas: A Review. iScience, 23(5), 101082. DOI: 10.1016/j.isci.2020.101082

[10] Morgan, E.R., Manwell, J.F., McGowan, J.G. (2017). Sustainable Ammonia Production from U.S. Offshore Wind Farms: A TechnoEconomic Review. ACS Sustainable Chemistry \& Engineering, 5(11), 9554-9567. DOI: 10.1021/acssuschemeng.7b02070 
[11] Guczi, L., Stefler, G., Geszti, O., Sajó, I., Pászti, Z., Tompos, A., Schay, Z. (2010). Methane dry reforming with CO2: A study on surface carbon species. Applied Catalysis A: General, $375(2), \quad 236-246$. DOI: 10.1016/j.apcata.2009.12.040

[12] Yunus, M.K., Ahmad, M.M., Inayat, A., Yusup, S. (2010). Simulation of enhanced biomass gasification for hydrogen production using iCON. World Academy of Science, Engineering and Technology, 62, 661-667.

[13] Lavoie, J.-M. (2014). Review on dry reforming of methane, a potentially more environmentally-friendly approach to the increasing natural gas exploitation. Frontiers in Chemistry, 2, 81. DOI: $10.3389 /$ fchem.2014.00081

[14] Aramouni, N.A.K., Touma, J.G., Tarboush, B.A., Zeaiter, J., Ahmad, M.N. (2018). Catalyst design for dry reforming of methane: Analysis review. Renewable and Sustainable Energy Reviews, 82, 2570-2585. DOI: 10.1016/j.rser.2017.09.076

[15] Hossain, M.A., Ayodele, B.V., Cheng, C.K., Khan, M.R. (2018). Syngas production from catalytic $\mathrm{CO} 2$ reforming of $\mathrm{CH} 4$ over $\mathrm{CaFe} 2 \mathrm{O} 4$ supported $\mathrm{Ni}$ and Co catalysts: Full factorial design screening. Bulletin of Chemical Reaction Engineering \& Catalysis, 13(1), 57-73. DOI: 10.9767/bcrec.13.1.1197.57-73

[16] Messaoudi, H., Thomas, S., Slyemi, S., Djaidja, A., Barama, A. (2020). Syngas production via methane dry reforming over La$\mathrm{Ni}-\mathrm{Co}$ and La-Ni-Cu catalysts with spinel and perovskite structures. Bulletin of Chemical Reaction Engineering \& Catalysis, 15(3), 885897. DOI: 10.9767/BCREC.15.3.9295.885-897
[17] Pino, L., Italiano, C., Laganà, M., Vita, A., Recupero, V. (2020). Kinetic study of the methane dry (CO2) reforming reaction over the Ce0.70La0.20Ni0.10O2- $\delta$ catalyst. Catalysis Science \& Technology, 10(8), 2652-2662. DOI: 10.1039/C9CY02192B

[18] Nagase, K., Shimodaira, T., Itoh, M., Zheng, Y. (1999). Kinetics and mechanisms of the reverse Boudouard reaction over metal carbonates in connection with the reactions of solid carbon with the metal carbonates. Physical Chemistry Chemical Physics, 1(24), 56595664. DOI: 10.1039/A906687J

[19] Khan, Z., Inayat, A., Yusup, S., Ahmad, M.M. (2015). Kinetic parameters determination using optimization approach in integrated catalytic adsorption steam gasification for hydrogen production. International Journal of Hydrogen Energy, 40(29), 8824-8832. DOI: 10.1016/j.ijhydene.2015.05.069

[20] Inayat, A., Ahmad, M.M., Mutalib, M.I.A., Yusup, S. (2012). Process modeling for parametric study on oil palm empty fruit bunch steam gasification for hydrogen production. Fuel Processing Technology, 93(1), 26-34. DOI: 10.1016/j.fuproc.2011.08.014

[21] Inayat, A., Khan, Z., Aslam, M., Shahbaz, M., Ahmad, M.M., Abdul Mutalib, M.I., Yusup, S. (2020). Integrated adsorption steam gasification for enhanced hydrogen production from palm waste at bench scale plant. International Journal of Hydrogen Energy, (In Press Article). DOI: 10.1016/j.ijhydene.2020.12.008

[22] Al-Ali, K., Kodama, S., Sekiguchi, H. (2014). Modeling and simulation of methane dry reforming in direct-contact bubble reactor. Solar Energy, 102, 45-55. DOI: 10.1016/j.solener.2014.01.010

Selected and Revised Papers from International Conference on Sustainable Energy and Catalysis 2021 (ICSEC 2021) (https://engineering.utm.my/chemicalenergy/icsec2021/) (School of Chemical and Energy Engineering, Faculty of Engineering, Universiti Teknologi Malaysia, 16-17th February 2021) after Peer-reviewed by Scientific Committee of ICSEC 2021 and Peer-Reviewers of Bulletin of Chemical Reaction Engineering \& Catalysis.

Editors (Guest) in this ICSEC 2021 section are Nor Aishah Saidina Amin, Mohd Asmadi Mohammed Yussuf, Salman Raza Naqvi, while Editor in Chief is I. Istadi. 